\title{
THE ROLE OF THE MICROBIOLOGIST IN THE TREATMENT AND REHABILITATION OF PATIENTS WITH SPINAL CORD INJURIES
}

\author{
By Rosemary Lindan, M.B., B.S., M.R.C.S., L.R.C.P. \\ Infectious Diseases Unit, Cuyahoga County Hospitals, Highland View, Cleveland, \\ Ohio 44122, U.S.A.
}

Abstract. Local and systemic infections represent major obstacles to the successful rehabilitation of patients following spinal cord injury. Their detection, prevertion and management are greatly aided by the inclusion of a microbiologist in the rehabilitation team and by the provision of a simple laboratory in close geographic proximity to the spinal cord injury unit. The role and scope of activities of the SCI team-microbiologist, and the suggested location and basic equipment for a small laboratory are described. Some of the advantages to be gained from such microbiological monitoring are discussed.

Key words: Microbiologist; Spinal cord injury unit; Rehabilitation team.

\section{Introduction}

INFECTIONS are still among the major hazards that lie on the road to rehabilitation and survival of the patient with a spinal cord injury. The prevention, early detection and appropriate treatment of pathogens, the recognition and management of 'colonizers', and the preservation and encouragement of a healthy normal flora, all require continuous microbiological monitoring of such patients and their immediate environment, and a critical scrutiny of the techniques used in their care.

The ritual collection of 'specimens' by medical or nursing staff and their dispatch to a distant laboratory cannot provide, by means of mere 'report slips', an accurate picture of the microbial landscape in the spinal cord injury ward.

The involvement of a microbiologist or infectious disease specialist, however, as an essential member of the spinal cord injury team, can result in the prompt provision of accurate information, which is needed to guide the antimicrobial therapy and antiseptic programmes along the narrow path between freedom from infection on the one hand, and conservation of the normal human bacterial flora on the other.

\section{The Ward Laboratory}

In a time of burgeoning computer technology and the sky-rocketing costs of sophisticated laboratory equipment, it is comforting to reflect that the essential needs of such a microbiologist are few and are becoming ever simpler, and even cheaper, to provide. My own laboratory and office at Highland View are located in a former ward utility room (Figs. I and 2) with only modest structural alterations, such as the obliteration of the bedpan hopper for instance, which as you can see is now partially covered by a new bench and a pleasing picture of a Swiss mountain. The basic equipment consists of a sink, a simple centrifuge, an incubator or two, refrigerator, autoclave, bunsen burners and a good microscope (the sink, refrigerator and autoclave come with the utility room in North America). With the availability of standardised dehydrated, or even prepoured, media and plastic 


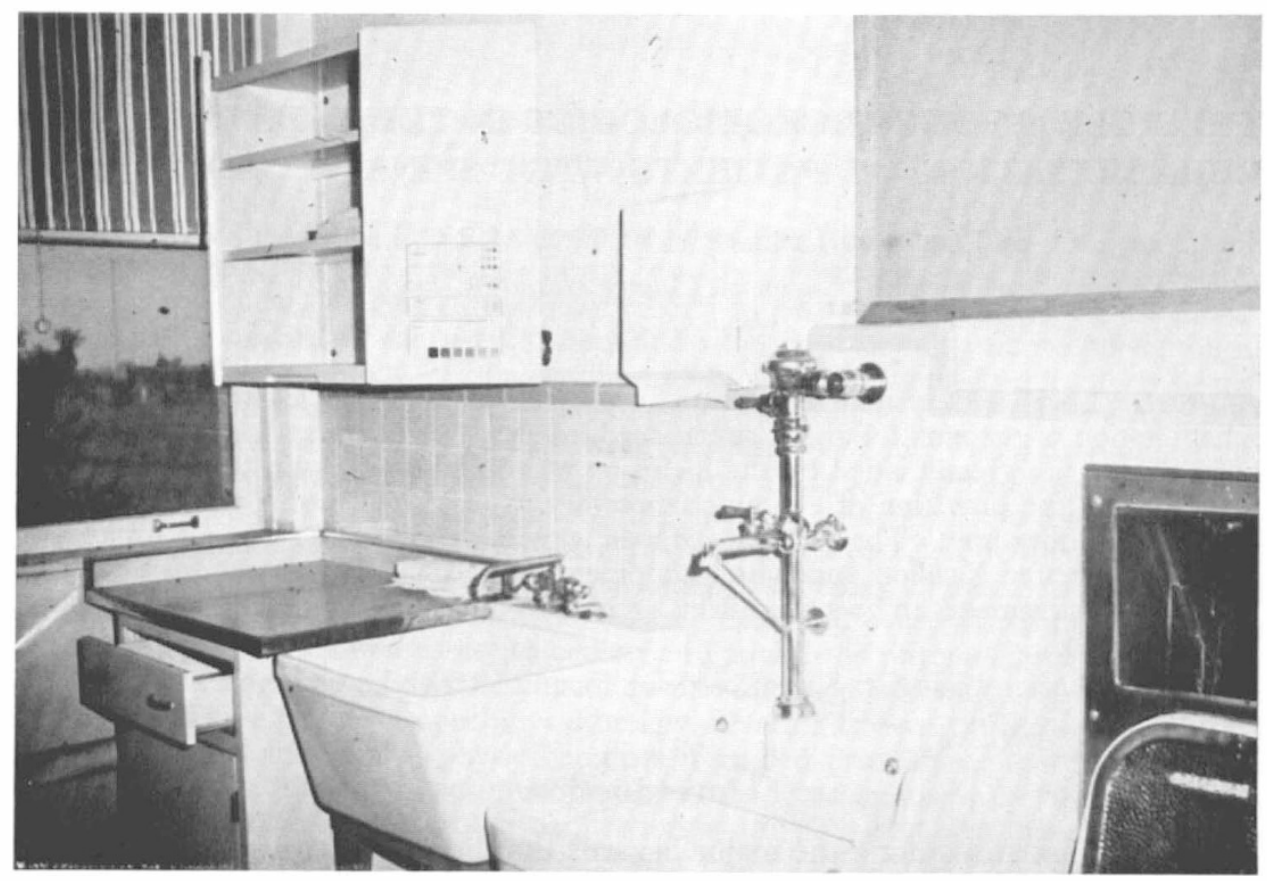

FIG. I

'Dirty' utility room (above) before conversion and (below) after conversion to microscope bench office area.

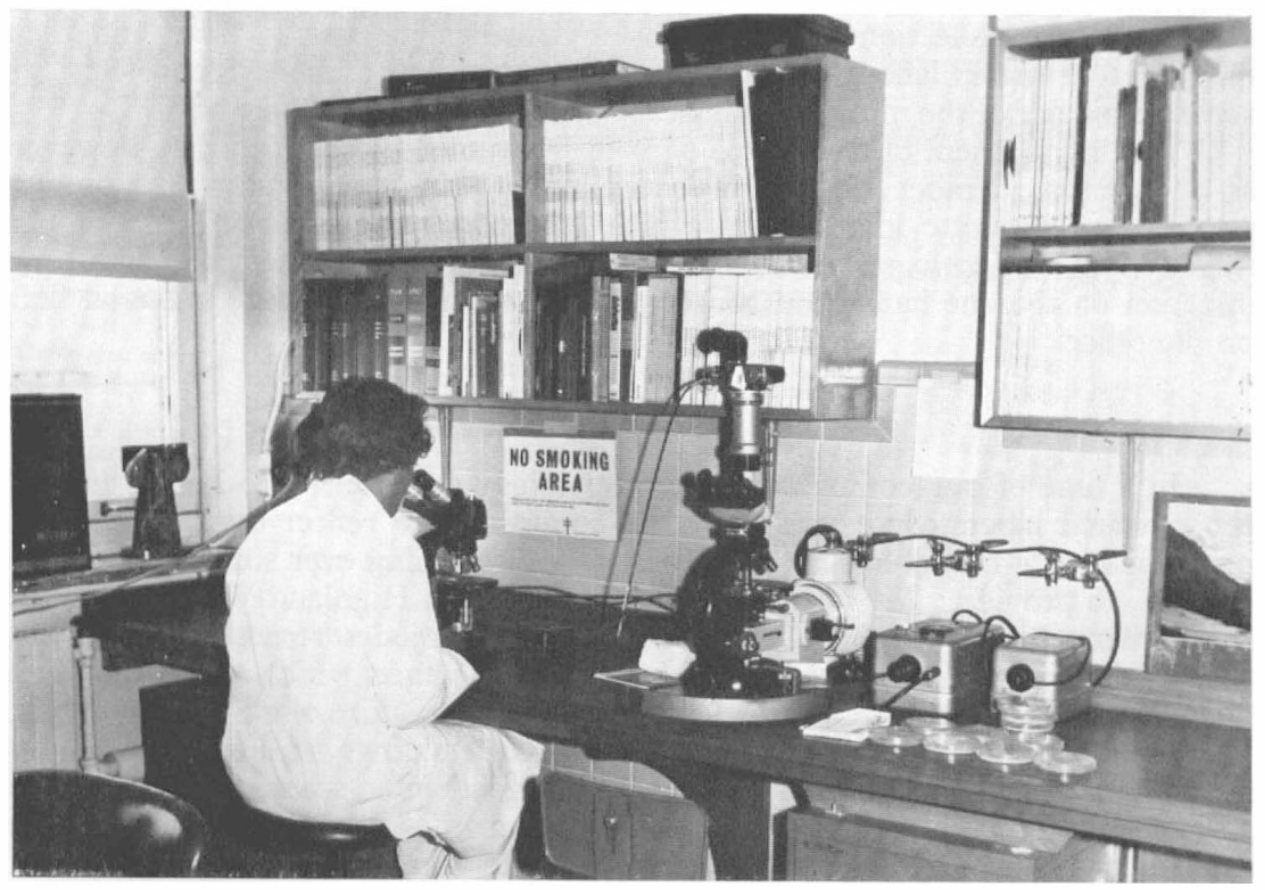




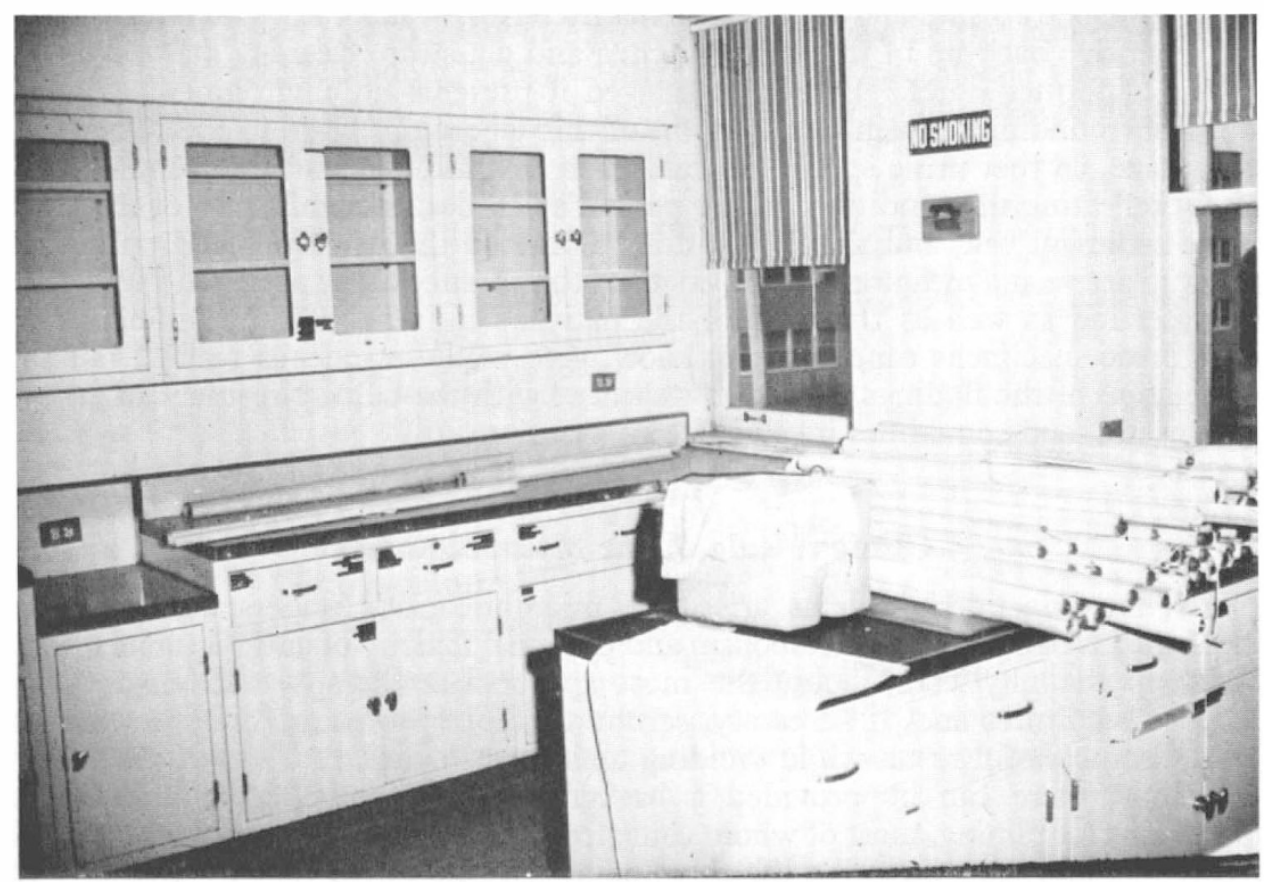

FIG. 2

'Clean' utility room (above) before conversion and (below) after conversion to laboratory.

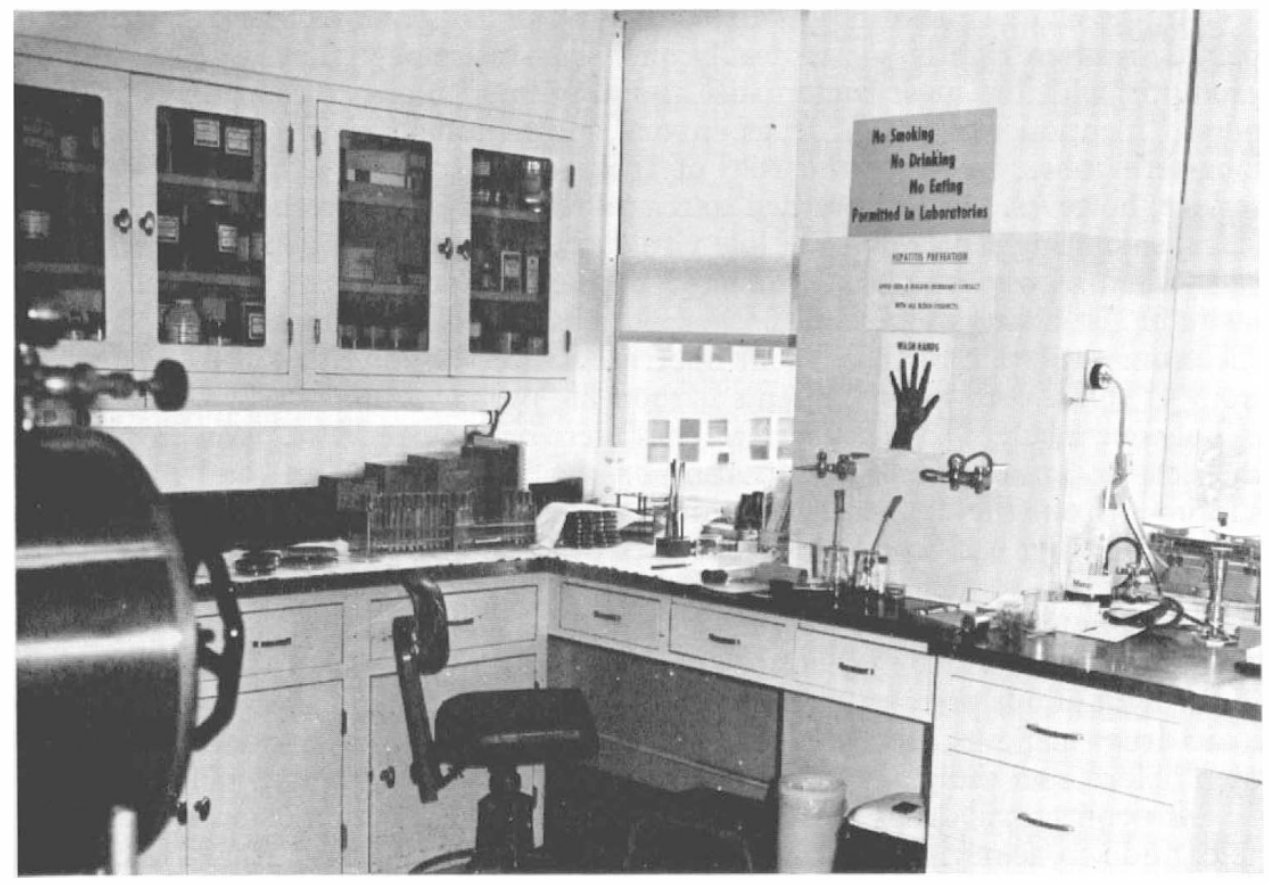


disposable petri dishes and pipettes, etc., a bacteriology laboratory no longer needs the extensive back-up of the media kitchen and glassware cleaning and sterilising rooms of former times. Properly managed it presents no environmental hazard to its surroundings and in fact location of this laboratory close to the ward is an advantage, so that urine specimens can reach it while still warm and more accurately reflecting the conditions in the patient's bladder. Examination of the fresh urine sediment can, and should, be done alongside the urinalysis and culture in order to arrive at a meaningful assessment of the absence of, or presence and degree of, infection as well as the state of the patient's kidneys. The examination of stale urine specimens can, as we all know, give wildly erroneous results, but the correlation of the findings in a fresh sediment with the culture results can always give useful, and sometimes invaluable, information.

\section{Clinical Role of the Microbiologist}

When infection problems arise, the microbiologist's understanding of the mechanisms of action, the metabolism and potential toxicity of antimicrobial drugs, can help the physician choose the most appropriate therapy, and ensure that follow-up cultures and, if necessary, serum antibiotic levels, are done in order to ensure a successful result while avoiding toxicity or 'overkill'.

Thus there can be provided a background of continuing experience for physicians in training, most of whom come fresh from the general teaching hospital where infections are viewed as life-threatening entities, rather than as episodic and largely preventable events in a long-term disability.

\section{Correlation of Clinical and Laboratory Studies}

In the acute general hospital such organisms as pseudomonas and serratia are regarded, often rightly so, as deadly and drug-resistant pathogens to be treated promptly with the most bactericidal and also, incidentally, the most nephrotoxic not to mention expensive, drugs in our antimicrobial armamentarium. From long-term observation of the role of these organisms on a spinal cord injury service, however, we have learned to regard them as being, in the vast majority of cases, colonising saprophytes of low virulence, only acting as opportunistic pathogens when all opposition is eliminated by immuno-suppression or deficit, leukopenia or the obliteration of all normal flora as a result of excessive use of broadspectrum antibiotics. In a recent fluorescent antibody study of urine specimens from 52 spinal cord injury patients harbouring pseudomonas or serratia organisms in only one instance so far (a serratia) has there been evidence of tissue invasion by the demonstration of antibody coating on the bacterial surface, and in a repeat specimen from the one positive patient we could not confirm it. In six cases, repeated testing has been carried out over periods of up to 2 years, during which the same species of bacteria, pseudomonas or serratia, were present either constantly or intermittently. We plan to continue such testing in order to identify any late invasion which may occur, and the circumstances which accompany it but, in the light of our present experience, we believe that to treat such organisms with toxic drugs achieves little since they usually return, possibly more drug-resistant then before, and the patient may have been harmed by the therapy.

If nephrotoxic drugs must be used, the assaying of serum levels is an invaluable guide to achieving effective therapy. One thing we have learnt since these 
simple serum assay tests became available, is how unreliable the 'routine recommended dose' is as a guide to effective therapy and we recommend that peak and trough serum levels should be assayed in every case where aminoglycoside therapy is needed for a serious infection.

\section{Laboratory Workload}

During 1976, our laboratory performed the following routine tests for the 24-bed spinal cord injury ward at Highland View.

$\begin{array}{lr}\text { Urinalysis and sediment examinations } & \text { IOI } 7 \\ \text { Urine cultures } & \text { I208 } \\ \text { Sensitivity tests } & 263 \\ \text { Antibiotic serum assays } & \text { I } 3 \\ \text { Sputum cultures } & 34 \\ \text { Throat cultures } & 35 \\ \text { Wound and pressure sore cultures } & \text { I I } 6\end{array}$

This laboratory also services the spinal cord injury follow-up clinic, identifies and then tracks any apparent mini-epidemics which may occur on the ward and monitors urinary drainage bags and any new catheter team equipment as well as respiratory and physical therapy equipment.

\section{Conclusion}

Any presentation, to lay or professional audiences, of the important concept of a team approach to spinal cord injury, always begins with an impressive list of those involved, starting with surgeons, physicans and nurses and proceeding on through therapists, social workers and technicians of various disciplines. I have not yet heard anyone presenting such a list which included a microbiologist or infectious disease specialist. He or she may be in there, disguised as a physician, but this does not make the point, which should be made, that infection stalks the patient with spinal cord injury and the truly complete team must provide a microbe hunter.

\section{RÉSUMÉ}

Les infections locales et systémiques reprèsentent un majeur problème dans la réhabilitation réussie des malades atteints d'une lésion spino-vértébrale. Leur découverte, prévention et traitement sont aidés beaucoup par la participation d'un microbiologique dans le 'rehabilitation team' et par l'équipment d'un simple laboratoire, géographiquement proche d'un tel centre spécialité. Le rôle it les divers activités d'un 'SCI-Team Microbiologist' ainsi que le logement avantageux et l'équipment élémentaire d'un tel laboratoire sont décrits. Quelques avantages réçus par contrôle microbiologique sont discutés.

\section{ZUSAMMENFASSUNG}

Lokale und systemsche Infektionen stellen das Hauptproblem fuer eine erfolgreiche Rehabilitation von Patienten mit Rueckenmarkverletzungen dar. Ihre Diagnose, Prophylaxe und Behandlung verdanken sie hauptsächlich der Mitarbeit eines Mikrobiologen im Rehabilitationsteam und der Einrichtung eines einfachen Laboratoriums in der Naehe eines Behandlungszentrums fuer Rueckenmarksverletzungen. Die Aufgabe und der Arbeitsbereich eines solchen Mikrobiologen, die gewuenschte Naehe des Labors und die Grundausruestung eines solchen kleinen Laboratoriums werden hier beschrieben. Einige Vorteile einer solchen Mikrobiologischen Kontrolle werden diskutiert. 